\title{
LETTERS
}

\section{Physician, Scribe, and Patient Perspectives on Clinical Scribes in Primary Care}

\author{
Ami Schattner, MD \\ The Faculty of Medicine, Hebrew University and Hadassah Medical School, Jerusalem, Israel.
}

J Gen Intern Med 32(3):243

DOI: $10.1007 / \mathrm{s} 11606-016-3889-6$

(c) Society of General Internal Medicine 2016

$\mathrm{N}$ ot long ago, a physician in any setting was assisted by a nurse at the patient's side and a secretary to deal with administrative chores.

Nowadays, physicians are increasingly relegating duties and responsibilities to others.

In addition to nurses and secretaries, we now have clinical dietitians, social workers, clinical pharmacists, behavior counselors, clinical librarians, physician assistants, and now, clinical scribes who are supposed to assist in gathering and documenting information. ${ }^{1}$

The introduction of such a plethora of specialized assistants into the once 'intimate' patient-physician relationship will certainly relieve some of the pressures so many physicians report, ${ }^{2}$ but potential adverse effects need to be better considered.

The physician's face time with the patient is already too short for effective patient-centered care and for establishing relationships which are based on the patient being known as a person, his or her feeling of being important to the physician, and the resulting trust, support, hope and adherence that together with informed decision-making, form the cornerstone of Healing. ${ }^{3}$

With the current over-burdened schedules, scribes may soon find themselves alone with the patient (possibly in the presence of a physician assistant), and the physician will get by reading the documentation gathered by the scribe from the screen at the expense of more eye-level, person-to-person essential contact with the patient.
Unlike the ideal presented by Yan et al., ${ }^{1}$ scribes will not make computer-gazing redundant, since crucial details of the clinical history, medications and tests will still need to be extracted and assimilated.

While using trained personnel in special areas to help physicians cope is to be commended, the intimacy-even sanctity - of the few minutes patients spend in private with their physician must not be violated.

Adopting the habit of studying the electronic health record (EHR) before the patient's entrance, then deserting the screen completely while concentrating and memorizing the patient's narrative and examination to be committed to paper or computer towards the conclusion of the encounter, ${ }^{4}$ will ensure better documentation and patient-physician relationship than any intervening scribe.

Corresponding Author: Ami Schattner, MD; The Faculty of MedicineHebrew University and Hadassah Medical School, Jerusalem, Israel (e-mail: amischatt@gmail.com).

\section{Compliance with Ethical Standards:}

Conflict of Interest: The author has no conflict of interest to disclose.

Funding: None.

\section{REFERENCES}

1. Yan C, Rose S, Rothberg MB, et al. Physician, scribe, and patient perspectives on clinical scribes in primary care. $J$ Gen Intern Med. 2016;31:990-5.

2. Linzer M, Poplau S, Bobbott S, et al. Worklife and wellness in academic general internal medicine: results from a national survey. J Gen Intern Med. 2016;31:1004-10.

3. Stange KC. The problem of fragmentation and the need for integrative solutions. Ann Fam Med. 2009;7:100-3.

4. Schattner A. "Computer-patient-physician" relationship. Int $J$ Clin Pract. 2014;68:790.

Published online November 10, 2016 